\title{
É O TRABALHO NA ENFERMAGEM UM PRINCÍPIO EDUCATIVO?
}

\author{
Delvair de Brito Alves*
}

\begin{abstract}
RESUMO: Neste ensaio, partimos de interpretações gramscianas, não apenas para identificarmos os princípios educativos que têm fundamentado os projetos de organização de Escolas de Enfermagem e do preparo de enfermeiro como, principalmente, para introduzirmos o trabalho como princípio educativo fundamental a esses projetos.
\end{abstract}

\begin{abstract}
In this essay, based on interpretations by Gramsci, not only do we identify the educative principles which are the foundation of the Nursing Schools and nurse education organization projects, but also introduce work as a fundamental educative principle to these projects.
\end{abstract}

\section{INTRODUÇÃO}

O princípio educativo que sustenta os projetos pedagógicos da enfermagem, em scus diferentes níveis, é redefinido à medida que a sociedade se desenvolve. Seria importante buscar, de forma aprof undada, a compreensão de como tem se construído o princípio educativo, e que princípios educativos têm fundamentado a organização das Escolas de Enfermagem e do preparo de enfermeiras. Entretanto, este é um contexto amplo e complexo que demanda exame aprof undado da literatura de enfermagem desde os seus primórdios, e que não comporta neste ensaio. Aqui, tentamos apenas uma primeira aproximação com o tema, resgatando alguns elementos da discussão teórica existente sobre o trabalho como princípio educativo, especialmente aqueles oriundos do pensamento de Gramsci e retomamos, apenas de forma breve, elementos que dão a marca dos princípios educativos assumidos pela enfermagem, em diferentes momentos históricos.

\section{O TRABALHO COMO PRINCÍPIO EDUCATIVO: ALGUNS ELEMENTOS TEÓRICOS}

MANACORDA $(6) * *$ e NOSELLA ${ }^{(10)}$ estudam o trabalho como princípio educativo em Gramsci a partir dos escritos que este pensador desenvolveu entre 1915 e 1937. Para eles, a temática pedagógica ocupa lugar central no pensamento de Gramsci, que toma como princípio educativo imanente da escola elementar e até mesmo de toda a escola unitária (escolas de primeiro e segundo graus), o trabalho entendido como modo próprio ao homem de participar ativamente da vida da natureza, para transformá-la e socializá-la. ${ }^{(6)}$

Para MANACORDA (6), os escritos entre 1916 e 1918 refletem o contacto de Gramsci com a classe operária e a crítica que ele faz à escola burguesa e ao reformismo socialista. Gramsci debate:

... a exigência de cultura para o proletariado, (...) e sobretudo a necessidade de sua organização; a busca de uma relação educativa que subtraia o proletariado à dependência dos intelectuais burguesese, finalmente, o problema específico da escola, (...) a relação entre instrução humanistica e formação profissional, que na crítica da escola burguesa existente envolve também a politica escolar socialista

MANACORDA (6) diz que Gramsci sugere uma escola que integre os dispersos princípios educativos da desagregação escolar atual, e que se apresente como escola de cultura e de trabalho ao mesmo tem-

* Enfermeira, Prof essora Adjunta da Escola de Enfermagem da UFBa, Mestre em Educação e Doutoranda em Educação.

** Trabalho publicado originalmente, e m italiano, sob o titulo In: PRINCÍPIO EDUCATIVOIN GRAMSCI, e m 1970, por Armando Editore. Roma. Em 1977, este mesmo trabalho é publicado em espanhol com o título: El principio educativo en Gramsci, por Salamanca. 
po, isto é, da ciência tomada produtiva e da prática tornada complexa. Para Gramsci, não se pode preparar para as atividades profissionais modernas, as quais se tornaram complexas e com as quais a ciência se encontra tão intimamente entrelaçada, sem ter como base uma cultura geral formativa tcórico-prática. Além de Gramsci, este autor retoma Lombardo Radice que critica os positivistas, acusando-os de identificar instrução com educação e por imporem ...um conteúdo determinado como típica encarnação de um ideal... criando assim ...o perigo que é próprio da escola não educativa: a esterilidade sistemática... (13)

$\mathrm{O}$ trabalho industrial é colocado como base e princípio do novo homem, princípio educativo e universal de toda a sociedade moderna.

O trabalho industrial, que implica, do ponto de vista intelectual, o conhecimento das leis da natureza e da sociedade e, do ponto de vista moral, o hábito de uin sistema de vida harmonicamente equilibrado, é, portanto, em última instância, o principio educativo unitário que, marxianamente, Gramsci aponta. A sua é uma posição igualmente crítica com relação ao velho principio dogmático e aristocrático e com relação às tentativas inovadoras que, permanecendo no interior da prática educativo-escolar imediata, correm o risco de cair, em nome da liberdade, no abandono ao conformismo mecânico do ambiente, sem conseguir efetuar um vinculo real e não esnobe com a atividade produtiva social. (...) sob o signo do trabalho e da ciência, o elemento que mais tem contribuido para unificar a humanidade. (6)

NOSELLA (10) diz que de acordo com MANACORDA, Gramsci aparece mais marxista do que Marx. Diz:

Ficará, aliás, evidente que Marx, mesmo partindo da necessidade não apenas do trabalho, mas também do sobretrabalho (social), colocageralmente fora do trabaIho o reino da liberdade(...); enquanto Gramsci (...) coloca o crescimento da personalidade não fora, mas sim dentro do trabalho.

KUENZER (5) também discute o princípio educativo em Gramsci, ao analisar o ensino de $1^{\circ}$ e $2^{\circ}$ graus. Em consonância com o pensamento gramisciano, ela diz que o avanço na construção de um projeto pedagógico mais articulado às necessidades da classe trabalhadora, exige que se comprecnda o princípio organizativo da escola contemporânea, em suas relações com a dinamicidade do processo de constituição da sociedade. A escola tcm sc dividido entre formar intelectuais e formar trabalhadores instrumentais.

Formar esses intelectuais é tarefa da escola que, para poder exercê-la, deve definir seu principio educativo a partir destas mesmas funções essenciais do mundo da produção econômica e que não se restringem ao modo de produzir mas abrangem todo o conjunto das superestruturas a ele dialeticamente relacionados, em suas dimensões jurídico-politicas e ideológicas. ${ }^{(5)}$

Ao lado de escolas, que têm como tarefa a formação de intelectuais, têm se desenvolvido escolas voltadas para o desempenho de funções instrumentais definidas pelos diferentes ramos da produção. Diz KUENZER (5)

Desta forma, a multiplicação das escolas profissionais representa não um desenvolvimento democrático como se crê geralmente, mas ao contrário, perpetua as diferenças sociais; esta falsa impressão de democratização decorre do fato de as escolas profissionais permitirem certa mobilidade social (...). Esta mobilidade, no entanto, é limitada pela origem de classe, que, dificultando o acesso ao saber cientifico tecnológico através da frequência aos niveis mais altos do sistema de ensino, delimita (...) ascens $\tilde{a} o$ na pirâmide ocupacional.

Esta autora recorre a MANACORDA (6), para dizer que Gramsci entende que todo o cidadão deve ser posto, mesmo que abstratamente, em condições gerais de ser dirigente. Diz ainda que, com o desenvolvimento das sociedades, a partir do avanço científico e tecnológico, entra em crise o princípio educativo fundamentado na divisão entre funções intelectuais e instrumentais, pois é impossível separar o homo faber do homo sapiens.

Do ponto de vista do exercicio profissional, à medida em que avança o desenvolvimento cientifico e tecnológico, as atividades práticas se tornam cada vez mais simplificadas no 'fazer', porém mais complexas em função do conhecimento cientifico que encerram, de tal modo que já não há distinção entre técnica e ciência. Para o operário, que não dispõe de 
alternativas de acesso ao saber, isto significa o seu crescente distanciamento do trabalho que executa, que passa a incorporar cada vez mais um conhecimento científico que ele não domina, (...) o 'trabalho simplificado é fruto da complexificação do saber científico-tecnológico', e, portanto, exige mais conhecimento do trabal hador para compreendê-lo, não obstante sua execução se ja simples. ${ }^{(5)}$

Ao tomar o trabalho como princípio educativo é permitido superar a cisão entre escola clássica e escola profissional, a princípio racional para o capitalismo, mas hoje superada por seu próprio desenvolvimento, tanto na cidade quanto no campo, pela cientifização de todo e qualquer trabalho prático. A escola, que unifica cultura e trabalho, tem como finalidade a formação do homem desenvolvido multilateralmente, que articula a sua capacidade produtiva às capacidades de pensar, de estudar, de dirigir ou de controlar quem dirige. Este princípio implica, necessariamente, a articulação entre teoria e prática e, scgundo KUENZER (5) :

$$
\begin{aligned}
& \text { É em Marx que se encontram os funda- } \\
& \text { mentos que permitem entender a relação } \\
& \text { teoria/prática - a práxis - como processo } \\
& \text { através do qual se constrói o conhecimen- } \\
& \text { to (...). O ponto de partida para essa pro- } \\
& \text { dução são os homens em sua atividade } \\
& \text { real, no trabalho - a çiência real começa } \\
& \text { na vida real, na atividade prática. }
\end{aligned}
$$

Assim, a situação vivida pelo trabalhador na sociedade capitalista é complexa, vez que o capital, ao se desenvolver, exige cada vez menos qualificação do trabalhador, enquanto que o desenvolvimento da sociedade cria relações sociais e forma de viver, que exigem que este mesmo trabalhador tenha cada vez mais conhecimentos que lhe permitam compreender, manipular e usuf nuir dos benefícios do avanço tecnológico. Este conhecimento científico-tecnológico que está na raiz da constituição da sociedade deve ser trabalhado pela escola.

Assim, a escola contemporânea * passa a ter como função duas tarefas contraditórias: formar o cidadão da polis, sujeito e objeto de direitos, e o trabalhador para atuar em um processo produtivo que limita a sua participação em atividade que requerem reflexão e criatividade. (5)

\section{TRABALHO, PRINCÍPIO EDUCATIVO PARA A ENFERMAGEM?}

O princípio educativo que dá sustentação aos projetos pedagógicos da enfermagem - em seus diferentes níveis - se redefinem em função de cada momento vivido por esse sub setor de saúde. A aproximação desse elcmento requer a retomada de algumas passagens de obras $(1,2,3,8,11,12,14)$ que marcaram a enfermagem, principalmente, por tratá-la sob diferentes ângulos e historicamente. Essas obras fornecem subsídios para afirmamos que o trabalho nem sempre foi tomado como princípio educativo nos projetos pedagógicos da enfermagem, aqui considerados, não apenas aqueles definidos por escolas mas, todos aqueles que explícita ou implicitamente conferem à enfermagem determinado perfil.

No período a.C. os escritos que se referem diretamente à enfermagem são escassos. As referências a essa atividade vêm concomitante com as da medicina. PAIXÃO ${ }^{(11)}$ diz que, de vários países estudados (Egito, Índia, Palestina, Assíria e Babilônia, Pérsia, China, Japão e Suécia), apenas em alguns há referências explicitadas à enfermagem:

Os hindus queriam que seus enfermeiros tivessem: asseio, habilidade, inteligência, conhecimento de arte culinária e de pre. paro dos remédios. Moralmente, deveriam ser: puros, dedicados e cooperadores. (11)

Nessa realidade, as doenças eram consideradas decorrentes de espíritos malignos. Segundo SIL$\mathrm{VA}^{(14)}$, essa é uma concepção própria do pré-capitalismo. Como exemplo cita que:

As sociedades tribais, primitivas, percebiam as enfermidades como provocadas pelos espiritos malignos, que habitavam $o$ interior de todos os seres (animados e inanimados) (...). Os feiticeiros, em cujas mãos se colocava a tarefa de cuidar dos doentes, uniam magia e religião ao conhecimento empirico de raizes, ervas $e$ frutas. (...) Quanto ao cuidado dos doentes e feridos, atividade complementar indispensável à cura, ficou a cargo das mulheres de suas familias; tarefa, então,

A preocupação com o papel da escola contemporânea tem sido exaustivamente tratada nos últimos anos. A formação do cidadão-trabalhador pela escola é objeto de discussão de teóricos, dentre os quais destacamos Miguel Arroyo. 
bastante semelhante às executadas por elas no ambiente doméstico (...). A origem etmológica do termo enfermagem, na lingua inglesa constitui uma das evidências da extrema semel hança existente, no passado, entre as referidas funções.

A Grécia contribuiu bastante para a evolução da medicina pois, Hipócrates (460 a.C.), traz uma nova concepção de doença, ao contrariar as crenças de serem as doenças causadas por maus espíritos e insistir na observação cuidadosa dos doentes, na cultura física, no culto à beleza, na importância ao dever da hospitalidade, elementos contributivos para o progresso da medicina e da enfermagem. (14)

A medicina romana, inicialmente mágica e exercida por escravos, é influenciada pela medicina grega. As necessidades decorrentes das guerras contínuas empreendidas pelo Império Romano, obrigam a imigrar médicos gregos. Entre os finais do século III e V d.C., a civilização romana recebe influências do ocidente, através da dif usão de suas idéias de despotismo, pessimismo e fatalismo e a idéia de religião que antes era, como a grega, terrena e prática, sem qualquer conteúdo espiritual ou ético, passa a contemplar graças espirituais numa vida depois da morte ${ }^{(14)}$

Nessas sociedades, atividades ditas de medicina e, principalmente, aquelas consideradas de enfermagem, são tidas como inf eriores. Em Roma, os serviços de medicina e de enfermagem são confiados a estrangeiros e escravos por serem indignos do cidadão romano. (8)

Essas breves passagens sobre a origem da enfermagem sugerem que o preparo daqueles que exercem atividades de medicina e de enfermagem, nesse período, tem como elemento educativo, as idéias de magias, de sobrenatural, associadas a idéias de castigo. Idéias essas que mantêm o homem prisioneiro do desconhecido, dificultando a sua colocação no mundo, como sujeito não sujeitado às leis das quais não participa.

Uma nova visão da doença surge com o Cristianismo, que a coloca como castigo divino, proveniente, contudo, de um Deus misericordioso e bom. Portanto, um instrumento poderoso de remissão dos pecados, de fortalecimento da fé, enfim, de aproximação com Cristo e salvação da vida eterna. Aqueles que cuidam dos enfermos têm, também, a oportunidade de salvar a própria alma. Com isto, a nova religião estimula, grandemente, $o$ atendimento aos pobres e doentes, favorecendo a constituição do diaconato (diáconos e diaconisas) com vistas à prática de cari- dade. (9) . Desta forma, o Cristianismo consegue aglutinar em torno da enfermagem, figuras ilustres na sociedade. Consegue fazer com que muitas das suas mais distintas damas se dediquem aos cuidados dos pobres e doentes. Sob a direção de São Jerônimo. destacam-se Santa Paula, Santa Fabíola e Marcela (3) Fazendo uma análise sobre esse grupo, PAIXÃO (11) diz:
Era, pois, um grupo de escola, aliando grande cultura e educação a elevado es- pirito de serviço. É este o primeiro grupo de mulheres, citado na história, que se dedicou a estudos profundos.

Essa ideologia continua de modo que, a organização da enfermagem sob a forma religiosa-militar, é grandemente influenciada pelas grandes abadessas como Santa Radegunda (século VI) c Santa Hildegarda (século XI). Nessa nova forma se destacam Os Cavaleiros de São João de Jerusalém, os de São Lázaro e os Cavaleiros Teutônicos. Os primeiros conseguem estender seus benefícios a diversos países europeus e mesmo com a expulsão dos cristãos de Jerusalém, eles transferem seu principal hospital para Rodes e Ilha de Malta. Notabilizam-se pelos cuidados aos hansenianos. Importante ainda na construção de uma enfermagem com espírito cristão, são as ordens seculares: Ordem dos Franciscanos, Convento das Religiosas, Ordens Terceiras. Esta última, considerada de grande valorpara a enfermagem pois a ela estão ligados personagens ilustres como: São Luis, Rei da França; Santa Isabel da Hungria; Santa Isabel de Portugal. A Ordem Dominicana está ligada Santa Catarina de Siena, que ... Não se contentava com servir doentes no hos pital. Procurava-os, abandonados pelas ruas ou em casebres, e providenciava sua internação. (11)

MELO ${ }^{(8)}$ diz que a Idade Média e os séculos XV e XVI são épocas de intensa religiosidade. A fé é explorada a ponto de serem vendidas indulgências perdão total ou parcial dos pecados - que garantem aos nobres e ricos a salvação após a morte. Esse fato precipita a Reforma Protestante, ou seja, o rompimento de uma parte dos cristãos com a Igre ja Católica, debilitando o seu poder. Esse período é conhecido entre nós, como o período negro da enfermagem pois ocorre o fechamento dos hospitais e a expulsão das religiosas que aí atuam. Como a enfermagem é função exclusiva da Igre ja, esse fato a atinge de modo profundo.

A falta de religiosas na Alemanha, na Inglaterra e em outros países que assumem o protestantismo, 
leva os governos a tomarem, a seu cargo, os hospitais e lotá-los com mulheres da mais baixa csfera: o tipo comum da enfermeira era da bêbada, desordeira, mulher de má vida. (11) Esse contexto faz com que as diaconisas dos primeiros séculos sejam lembradas. Entretanto, Lutero, apesar de também se preocupar com essa situação, considera essa idéia irrealizável no protestantismo.

Segundo FOUCAULT (4), a reorganização dos hospitais militares no século XVII visando o cuidado aos soldados, baseia-se na disciplina e isto muito influencia a enfermagem. Nesse século, há uma retomada da filosofia baseada no Cristianismo, na formação de pessoas para cuidar de doentes. Surgem os precursores da enfermagem moderna, ou seja, São Vicente de Paula e Santa Luiza de Marillac, que organizam as Filhas de Caridade (conhecidas como Irmãs de Caridade). Em 1633, Santa Luiza de Marillac reúne essas Filhas para formar-lhes o caráter e instruí-las nos misteres que deveriam desempenhar, $\mathrm{e}$ São Vicente procura formar nas senhoras ricas, mentalidade e personalidade cristãs, forna-las no espírito da fraternidade cristã. (11) Essas irntãs têm sucesso na direção de hospitais e passam a atuar em todos os continentes, de modo que, em 1930, há em torno de 400.000 Irmãs de Caridade.

O cristianismo introduz, portanto, o espírito de servir, a prática de caridade, como elementos necessários à salvação da alma. É este princípio que passa a marcar a enfermagem como atividade a serviço de Deus, dos homens e dos próprios exercentes da enfermagem, um princípio educativo fortemente trabalhado pela precursora da enfermagem moderna, Florence Nightingale, e internalizado, até mesmo na sociedade capitalista, onde, mais importante do que a salvação da alma, é a salvação dos corpos necessários ao sistema produtivo. A extrema religiosidade vivida pelos exercentes da enfermagem constitui um poderoso reforço ao espírito de subserviência originário nos primeiros enfermeiros.

É sob este terreno, religiosamente fértil, que nasce, com Florence Nightingale, a enfermagem moderna. Com a falta de pessoal religioso, conseqüente das Reformas Protestante e Católica, o pastor Fliedner, do Instituto da Kaiserwerth, na Alemanha, apela por pessoas ... dispostas à inteira abnegação de si mesmas a serviço do próximo. (11) A experiência desse Instituto chega ao conhecimento de Florence Nightingale, filha de pais ingleses ricos, com uma cultura incomum às mulheres de sua época: fala vários idiomas e domina matemática. Essa "lady" estagia nesse
Instituto, após o que abre escolas (...) às moças educadas, e cultas, como uma profissão honrosa e capaz de torná-las felizes". (11) Com a sua atuação na Guerra da Criméia (1854) Florence consegue, juntamente com 38 voluntárias (religiosas e leigas), diminuir o índice de mortalidade entre os soldados feridos. Após a guerra é contemplada pelo governo inglês com uma doação que lhe permite abrir a Escola de Enf ermagem no Hospital São Tomás, com o objetivo de reformar a enfermagem que se encontrava dividida entre dois (2) grupos de pessoas a serviço de doentes:

...o primeiro, diminuto, compunha-se de
religiosas católicas e anglicanas, que co-
meçavam apenas a se organizar; o segun-
do numeroso, era formado de pessoas sem
educação e sem moral. A maioria se em-
briagava. (11)

O sistema de Florence Nightingale prevê que a atividade de enfermagem só deve ser exercida por mulheres que são preparadas ou como "nurses" (responsáveis pelas atividade manuais) ou como "ladies nurses"'(responsáveis pelo ensino, supervisão e administração da enfermagem). É una atividade não remunerada, que exige espírito de abnegação, de servir, de obediência, além de disciplina rigorosa. ${ }^{(1)}$

Esse modelo é transportado para o Canadá, Estados Unidos, França, Alemanha, Suécia, dentre outros países, inclusive alguns da América Latina.

No Brasil, o pensamento místico marca a primeira concepção de saúde. Iniciada a colonização, novas doenças são introduzidas e o seu tratamento consiste em tirar do corpo doente o ef eito dos malefícios ou do desagrado dos deuses. A mudança no quadro nosológico demanda assistência não apenas dos pagés, mas dos físicos, cirurgiões, cinurgiões-barbeiros, barbeiros, algebristas, curiosos, boticários, anatômicos, curandeiros, entendidos e outros. As mulheres aparecem na saúde como religiosas, como parteiras leigas e como voluntárias. Às primeiras, coube o trabalho caritativo e de assistência ao corpo e ao espírito, nas Santas Casas; as parteiras, institucionalizadas em 1832, responsabilizam-se pela assistência ao parto e à parturiente e as voluntárias notabilizamse pelos serviços prestados à pátria. (12)

O trabalho caritativo, como precursor do trabalho de enfernagem, não se diferencia do trabalho das irmãs de caridade, dos padres, irmãos ou jesuítas. No Brasil, a história destaca o trabalho do franciscano frei Fabiano e do jesuíta padre Anchieta, na assistência à saúde. Quanto ao trabalho voluntário, são encontrados registros do século XVII. da atuação de Francisca 
Sande -baiana (nasceu no final do século XVII e morreu em 1702) e Ana Justina Ferreira Neri. O trabalho voluntário de Ana Neri não tem qualquer relação com um trabalho do tipo profissional e sim, motivado pelo espírito cristão, caritativo e pelo sentimento cívico. Sua história assemelha-se, apenas em parte, à história de Florence Nightingale por que esta última, embora tenha servido à Guerra da Criméia, dispunha de algum treinamento profissional, enquanto que Ana Neri não dispunha de qualquer tipo de treinamento. Além deste fato, Florence, tão logo terminou a Guerra, passou a investir na formação de pessoal para atuar na enfermagem. (12)

Ao analisar o trabalho caritativo e a idcologia da submissão esta autora diz:

\begin{abstract}
$A$ vertente do trabalho caritativo e religiosos foi muito importante e hegemonizou a ideologia e o trabalho da enfermagem por longo periodo após o advento do Cristianismo e sua persistência como doutrina religiosa poderosa em todo o mundo ocidental. Na enfermagem essa influência foi tão grande, que até hoje o seu trabalho é visto como parte da assistência cariativa e, os profissionais de enfermagem, como exemplo de abnegação, de vida ascética e de dedicação aos pobres desvalidos e necessitados de ajuda. (...) A ideologia dominante na enfermagem brasileira, até a década de 80 pelo menos, reproduz acriticamente esta caracteristica da religiosidade e espirito caritativo. (12)
\end{abstract}

Esta marca é alimentada por Carlos Chagas, ao tomar para si a iniciativa da criação da primeira Escola de Enfermagem de alto padrão nos moldes Nightingale. A primeira diretora dessa escola, uma americana, Miss Clara Louise Kienminger, dá início ao curso em 19.2.1923 e, em 1926, a Escola passa a ser chamada Escola de Enfermagem Anna Nery (voluntária leiga, da Guerra do Paraguai, que atuou com profunda dedicação aos soldados feridos nessa guerra, sendo homenageada pelo governo brasileiro como mãe dos brasileiros). Essa Escola nasce para atender exigências do Serviço de Saúde pública e não hospitalar, como ocorre em outros países. Segundo ALCÂNTARA (1), a enf ermagem como profissão feminina, nasce identificada com o papel materno (enfermeira como substituta da mãe para os doentes) e com o trabalho missionário das religiosas (sacrificado e sublime).

O princípio educativo, expressão do ideal de servir, sustentado pela religiosidade e pelo espírito de servir à pátria, continua sendo o dominante na formação de pessoal para desenvolver atividades não instrumentais (não manuais).na enfermagem. As demandas decorrentes do processo de industrialização brasileiro, ao lado da deficiência numérica de enfermeiras, provocam o aparecimento de escolas voltadas para o desempenho de funções instrumentais, ou seja, escolas para formação de auxiliares de enfermagem (a partir da década de quarenta) e de formação de técnicos de enfermagem (a partir da década de sessenta), todas elas reproduzindo o mesmo princípio assumido pelas escolas de formação de enfermeiras.

\section{ALGUMAS CONSIDERAÇÕES FINAIS}

A realidade do final do século $\mathrm{XX}$ não mais comporta os princípios educativos que fundamentam a formação de pessoal para cuidar de doentes, nos séculos e nas décadas passadas. $O$ ideal de servir fundamenta-se numa religiosidade extrema, incompatível com a necessidade de sobreviver na sociedade contemporânea, onde as Escolas de Enfermagem têm duas tarefas contraditórias: formar o cidadão enfermeiro e o profissional enf ermeiro. A concretude desta tarefa requer muita competência político-pedagógica, pois

...o preparo que a cidadania exige nas sociedades democráticas, fundamentadas na igualdade de oportunidades e nos direitos humanos, é incompativel com o preparo que o sistema produtivo requer, fundamentado na hierarquia, na disciplina, no autoritarismo, na desqualificação. (5)

O trabalho, como a escola, tem dimensões contraditórias, ou seja, ele é, ao mesmo tempo, educativo e deseducativo, qualificado e desqualificado. Entretanto, ao ser tomado como princípio educativo pelos projetos pedagógicos das Escolas de Enfermagem, oportunidades serão criadas para que, tanto os enfermeiros como as demais categorias que exercem a enfermagem, passem a compreender que a sua prática é um trabalho assalariado, coletivo, fragmentado, explorado, que demanda mudanças capazes de colocar a enfermagem em posição de dignidade diante do setor saúde. 


\section{REFERÊNCIAS BIBLIOGRÁFICAS}

1. ALCÂNTARA, Glete de. A enfermagem moderna como categoria profissional: obstáculos à sua expansão na sociedade brasileira. Ribeirão Preto: 1966. 117p.

2. ALMEIDA, Cecilia Maria Puntel de; ROCHA, Juan Stuardo Yazlle. $O$ saber de enfermagem e sua dimensão prática. São Paulo: Cortez, 1986.

3. DOLAN, Josephine A. History of Nursing. 10 ed. Philadelphia: Saunders Campany, 1958. 422 p.

4. FOUCAULT, Michel. Microfisica do poder. Tradução por Roberto Machado. Rio de Janeiro: Graal, 1979, 296 p.

5. KUENZER, Acácia. Ensino do $2^{\circ}$ grau: o trabalho como principio educativo. São Paulo: Cortez, 1988, p. 97-149.

6. MANACORDA, Mario A. O principio educativo em Grams$c i$ : Tradução por William Lagos. Porto Alegre: Artes Médicas. 1990. (Educação, teoria e crítica). 288 p.

7. $\quad$ O $\quad$ princípio educativo em Gramsci: Tradução por William Lagos. Porto Alegre: Artes Médicas. 1990. p. 199 (Educação, teoria e crítica). apud KUENZER, Acácia. Ensino do $2^{\circ}$ grau: o trabalho como principio educativo. São Paulo: Cortez, 1988, p. 121.
8. MELO, Cristina Maria Meira de. Divisão social do trabalho e enfermagem. São Paulo: Cortez, 1986. 94 p. (Série Saúde e Sociedade).

9. MOLINA, Teresa Maria. História de la enfermeria. $2^{\mathrm{a}}$ ed. Buenos Aires: Inter-Médica, 1973. 169 p.

10. NOSELLA, Paolo. O trabalho como principio educativo em Gramsci. In: SILVA, Tomaz Tadeu da et alii. Trabalho, Educação e prática social: por uma teoria da formação humana. Porto Alegre: Artes Médicas, 1991. 273 p. (Educação, teoria e critica)

11. PAIXÃO, Waleska. Páginas de história de enfermagem. $3^{3} \mathrm{ed}$. Rio de Janeiro: Bruno Buccini, 1963. 112 p.

12. PIRES, Denise. Hegemonia médica na saúde e a enfermagem. São Paulo: Cortez, 1989. 156 p.

13. RADICE, Lombardo. Educazione e diseducazione. Bemporad, La Voce, Firenze, 1923, p. 102-14, apud MANACORDA, Mario A. O principio educativo em Gramsci. Tradução por William Lagos. Porto Alegre: Artes Médicas, 1990, p. 174. (Educação, teoria e crítica).

14. SILVA, Graciete Borges da. Enfermagem profissional: análise crítica. São paulo: Cortez, 1986. 143 p. 